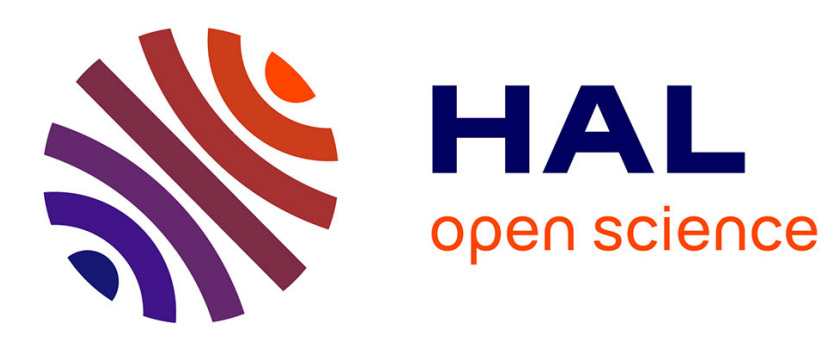

\title{
Finger flexors fatigue in trained rock climbers and untrained sedentary subjects
}

Franck Quaine, Laurent Vigouroux, Luc Martin

\section{To cite this version:}

Franck Quaine, Laurent Vigouroux, Luc Martin. Finger flexors fatigue in trained rock climbers and untrained sedentary subjects. International Journal of Sports Medicine, 2003. hal-01635475

\section{HAL Id: hal-01635475 \\ https://hal.science/hal-01635475}

Submitted on 15 Nov 2017

HAL is a multi-disciplinary open access archive for the deposit and dissemination of scientific research documents, whether they are published or not. The documents may come from teaching and research institutions in France or abroad, or from public or private research centers.
L'archive ouverte pluridisciplinaire HAL, est destinée au dépôt et à la diffusion de documents scientifiques de niveau recherche, publiés ou non, émanant des établissements d'enseignement et de recherche français ou étrangers, des laboratoires publics ou privés. 


\section{Finger Flexors Fatigue in Trained Rock Climbers and Untrained Sedentary Subjects}

F. Quaine

L. Vigouroux

L. Martin

\section{Abstract}

The present series of experiments were conducted to access the surface EMG frequency parameters during repeated fingertip isometric contractions to determine if they can be used as a fatigue index under specific grip used in rock climbing. Electromyograms of the finger flexors and extensors were characterised in ten elite climbers and ten non-climbers. The exercise consisted in reaching $80 \%$ of maximal isometric finger force as quickly as possible intermittently with a 5-s contraction followed by 5 -s of rest until exhaustion (i.e. when the subject was unable to maintain $80-70 \% \mathrm{MVC}$ force range for the $5 \mathrm{~s}$ ). The results clearly indicate that expert climbers performed significantly greater fingertip force than sedentary subjects $(420 \pm 46 \mathrm{~N}$ vs. $342 \pm 56 \mathrm{~N}$ ). This force was maintained during twelve repetitions $(12.88 \pm 4.96)$ in sedentary subjects, whereas the climbers maintained the force during nineteen repetitions $(19.33 \pm 4.84)$. The median frequency of both the flexor and extensor EMG power spectra decreased during fatiguing isometric contractions, but at different rates in climbers and non-climbers. In non-climbers, the results replicated previous findings, whereas in climbers the results were novel.

\section{Key words}

Muscular fatigue · fingertip force · biomechanics · rock climbing

There has been remarkable development in the scope and quality of rock climbing in the last few years. The hands are used as tools for the ascent, and many of the external supporting forces are applied upon the fingers and also distributed through the wrist, elbow and shoulder [3]. Three quarters of elite and recreational sport climbers suffer from injuries of the hand [16]. Only one study exhibited an electromyographic analysis of the arm muscles during climbing [10]. However, this study remains far away from the activity, since the task corresponded to a basic pull-up (the authors focussed more on the muscles crossing the elbow joint rather than fingers muscles). It thus seems important to find out the degree of exertion of the involved finger muscles during a gripping task which accurately mimics the grip used in rock climbing.

Fatigue, defined as the inability to produce the required force [21], is a major factor of fall and injury [3]. The influence of fatigue on EMG parameters during static intermittent sub-maximal voluntary muscle contractions is well documented in the literature $[2,9,19]$. The EMG frequency parameters decrease toward lower frequencies with fatigue, which mainly results from the decrease in muscle fiber conduction velocity [7]. Few studies have reported muscular endurance data concerning climbers and the mode of investigation varies. Muscular endurance was measured in both sustained and rhythmic isometric handgrip exercises at $40 \%$ of maximal voluntary contraction [8]. The results showed no significant different maximal force and endurance time between climbers and non-climbers during sustained contraction, while the intermittent time for climbers was twice as long as for non-climbers.

The purpose of the present study was to analyze fingertip force and electromyographic parameters of elite climbers and non- 
climbers with fatigue in forearm muscles (finger flexors and extensors) in a grip posture close to rock climbing conditions. Knowledge of muscle involvement associated to hold grasping and the constraints it involves on the force production and the rate of fatigue may be useful to prevent musculo-skeletal diseases, to improve simulated handhold shapes and to increase safety.

\section{Material and Methods}

\section{Subjects}

A total of 20 right hand-preferred male subjects took part in this study. Ten subjects (age: $24 \pm 1.8 \mathrm{y}$; height: $178.1 \pm 5 \mathrm{~cm}$; body mass: $74 \pm 3 \mathrm{~kg}$ ) were novices (labeled SED in the text) in rock climbing. Ten subjects (age: $22 \pm 1.4 \mathrm{y}$; height: $177.4 \pm 4.5 \mathrm{~cm}$; body mass: $65.6 \pm 2 \mathrm{~kg}$ ) were elite rock climbers (labeled CLB) recruited from the best national French climbers (French 8a or 5.13 a Y.D.S on sight, which corresponds to the world cup level). All subjects gave their written informed consent.

The subjects were seated in a chair and instructed to keep the anterior surface of their forearm on a table. The wrist was fixed thanks to a mitten at $40^{\circ}$ of extension in front of the hold. The upper arm was at $45^{\circ}$ of abduction, the elbow joint being flexed at 90 . The distance between the hold and the support point of wrist fixation was $1 / 3$ of the length of the third finger and induced a "crimp" grip posture as proposed by Schweizer [18]. The degree of the flexion was measured using a digital camera located $0.70 \mathrm{~m}$ above the device. This camera measured the sagittal index finger posture. Two markers were aligned with the longitudinal axis of the segment. The angle of intersection of the lines of adjacent segments defined the joint angles. They were assumed to be similar for the four fingers. The proximal interphalangeal joints are flexed from $90^{\circ}$ to $100^{\circ}$ and the distal interphalangeal joints are hyperextended.

The hold consisted of a steel plate $(100 \times 20 \times 3 \mathrm{~mm})$ covered with a non-skid surface fastened to the force sensor. The fingers gripped the hold on a one centimeter deep surface. The thumb did not act as an additional gripping force. A second stop was fastened behind the elbow. Consequently, the fingertip force generated resulted only from isometric finger flexor muscle contractions.

The subjects warmed up on the device by carrying out a series of twenty contractions for $5 \mathrm{~s}$ at $50 \mathrm{~N}$ (chosen arbitrarily). After a 3 min rest, the subjects performed three maximal isometric finger flexion contractions for $5 \mathrm{~s}$ separated by a 5 -min resting period. The highest peak force generated was adopted as maximal voluntary contraction force (MVC). During pre-test experiments, we tested that the warm-up exercise did not induce fatigue in climbers nor in non-climbers.

After ten minutes rest, the subjects carried out as quickly as possible finger flexion contractions at $80 \%$ MVC during $5 \mathrm{~s}$ followed by $5 \mathrm{~s}$ of rest. The contractions were continued until exhaustion, defined as the point when the subjects were unable to maintain $-10 \%$ of the initial target force (i.e. $80-70 \%$ MVC range) for the required $5 \mathrm{~s}$. Each subject was given oral encouragement and was provided with an ongoing force output which was displayed on a computer screen to confirm his achievement throughout the test.

Surface EMG activity was recorded from extrinsic muscles of the hand during each test session. In power gripping, the extrinsic muscles of the hand, especially the flexor digitorum superficialis and/or profundus, provide most of the force [1]. The flexor muscles were located by asking the subject to flex the four fingers against external resistance while visually observing and palpating the forearm over the contracting muscle. To ensure that the flexor carpi radialis (a wrist flexor) was not contributing significantly to the EMG signal, electrode placement was considered appropriate when the EMG signal was present during fingers' flexion with a voluntary stable wrist, yet absent during wrist flexion with no voluntary finger flexion [4]. Concerning the extensor muscles, the electrodes were placed around the $1 / 4$ point on a line drawn from the lateral epicondyle to the styloid process of the ulna [1]. The electrodes were located parallel to the assumed longitudinal axis of the muscle fibers. Pre-amplifier electrodes $(\times 600)$ were used (input impedance $10 \mathrm{G} \Omega$, common mode rejection ratio $=100 \mathrm{db}$ at $50 / 60 \mathrm{~Hz}$, bandwidth $=5$ $1000 \mathrm{~Hz}$ ) with self adhesive, pregelled silver/silver chloride Medi-Trace (Graphic Controls, Canada) patch. The skin was cleaned (alcohol) and abraded prior to the application of the electrode in a bipolar configuration. Interelectrode distance was $20 \mathrm{~mm}$ and interelectrode resistance was inferior to $10 \mathrm{k} \Omega$. A mono-axial load cell (Slumberger, model CD-750) was used to measure the external horizontal force applied to the hold. The signal was amplified (PM, model 1965) and force and EMG were recorded (Mazet Electronique, model Biostim 6082, France) at $1024 \mathrm{~Hz}$.

The number of contractions a subject was able to keep the force level within the $80-70 \% \mathrm{MVC}$ range was measured and converted into time to fatigue (TF). For each contraction, the raw EMG were low pass filtered $(300 \mathrm{~Hz}$ cutoff, zero lag fourth order Butterworth filter). Each 5-s squeeze (force and EMG) was divided into 2-s segments adjusted two seconds after the onset of the force increase to eliminate start effects. A Fast Fourier Transform (FFT) with 512 points was used to transform each 2-s EMG segment. Median Frequencies $\left(f_{\text {med }}\right)$ were computed for each muscle. $f_{\text {med }}$ values were expressed relative to their MVC values and used as fatigue indexes. The time-related behavior of $f_{\text {med }}$ for each muscle was plotted and the slope of the line of best fit was computed. Each subject provided two slopes (flexor and extensor), one MVC fingertip force and one TF value. All computation procedures were performed using Matlab software (The Math Works, Inc). Descriptive statistics are means \pm SEM. Independent group t-tests of significance were used to identify significant differences in MVC force and TF value between SED and CLB. A twoway ANOVA with repeated measures $(2 \times 2$, Subject group $\times$ Muscle) with Tukey post hoc tests was used to analyze the differences in slopes of $f_{\text {med }}$. The interaction Subject group $\times$ Muscle highlights the various changes of EMG frequency parameters in the flexor and extensor between the subjects. 


\section{Results}

Maximal voluntary force test (Fig. 1)

The comparison of the two groups using a bilateral t-test indicated that the climbers performed significantly greater fingertip forces than the non-climbers $(t=2.62, p<0.05)$. The maximum forces exerted by the sedentary subjects amounted to $342 \pm 56$ $\mathrm{N}$, whereas the climbers' MVC equaled $420 \pm 46 \mathrm{~N}$.

\section{Time to fatigue results (TF)}

The times to fatigue data are presented in Fig. 1. A significant difference between the times to fatigue was observed between SED and $\operatorname{CLB}(\mathrm{t}=2.5, \mathrm{p}<0.033)$. SED maintained the required fingertip force during 12 contractions, which corresponds to $1 \mathrm{~min}$ and $55 \mathrm{~s}$ before the grip was released. CLB performed the exercise during 19 contractions which corresponds to $3 \mathrm{~min}$ and $5 \mathrm{~s}$.

\section{EMG indices results}

Fig. 2 illustrates the drop in $f_{\text {med }}$ for each muscle in the sedentary and climber subjects. Negative $f_{\text {med }}$ slopes were exhibited for each muscle. The most significant slopes were observed in the sedentary subjects' flexor and extensor (mean slope $=2.09$ ), whereas the ones observed in CLB (mean slope $=0.87$ ) were around 2.5 times inferior.

\section{Statistics}

The statistical tests of the slopes differences are illustrated in Fig. 3. The ANOVA results showed a significant effect of Subject group $(\mathrm{F}[1,13]=7.9, \mathrm{p}<0.01)$. The $f_{\text {med }}$ slope was less marked in the climbers than in the sedentary subjects, whatever the muscle. No significant effect of Muscle was observed. The $f_{\text {med }}$ slope in the flexors was similar to the one observed in the extensors,

whatever the category of subjects. No significant interaction Subject group $\times$ Muscle was observed. The $f_{\text {med }}$ slopes in the flexor and in the extensor were higher in SED and proportionally decreased in CLB.

\section{Discussion}

The present study was performed to characterize the forearm muscles exertion during fatigue induced by sub-maximal repetitive rock climbing grip exercise. Fingertip force, time to exhaustion and neuromuscular recruitment adaptation associated to fatigue were analyzed in elite climbers and non-climbers.

The results clearly indicate that expert climbers generate a significantly greater fingertip force than sedentary subjects. This finding confirms previous reports [6], although the present force values were lower. These differences can be explained by the experimental protocol characterized by the requirement of fingertip forces instead of whole hand grip forces [6]. Electromyograms of the finger flexors and extensors in climbers and non-climbers demonstrated that these muscles were similarly involved in the grip. This result does not agree with previous findings which show that co-activation decreases in trained subjects $[5,15,17]$. Nevertheless, biomechanical considerations show that the external force is applied at the fingertip in rock climbing, which requires specific finger extensor tensions in order to balance finger joint torques $[11,18,20]$.

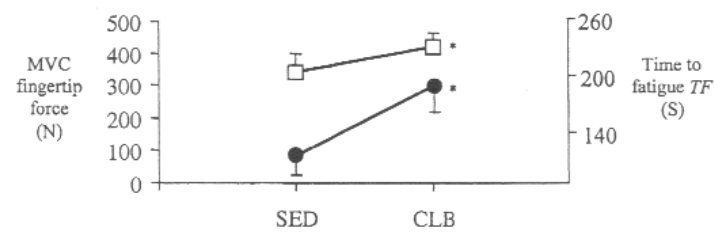

Fig. 1 MVC absolute fingertip force $(\square)$ and time to fatigue $(\bullet)$ in sed entary (SED) and climber (CLB) subjects. Errors bars indicate standard errors. " indicates a significant difference between SED and CLB.
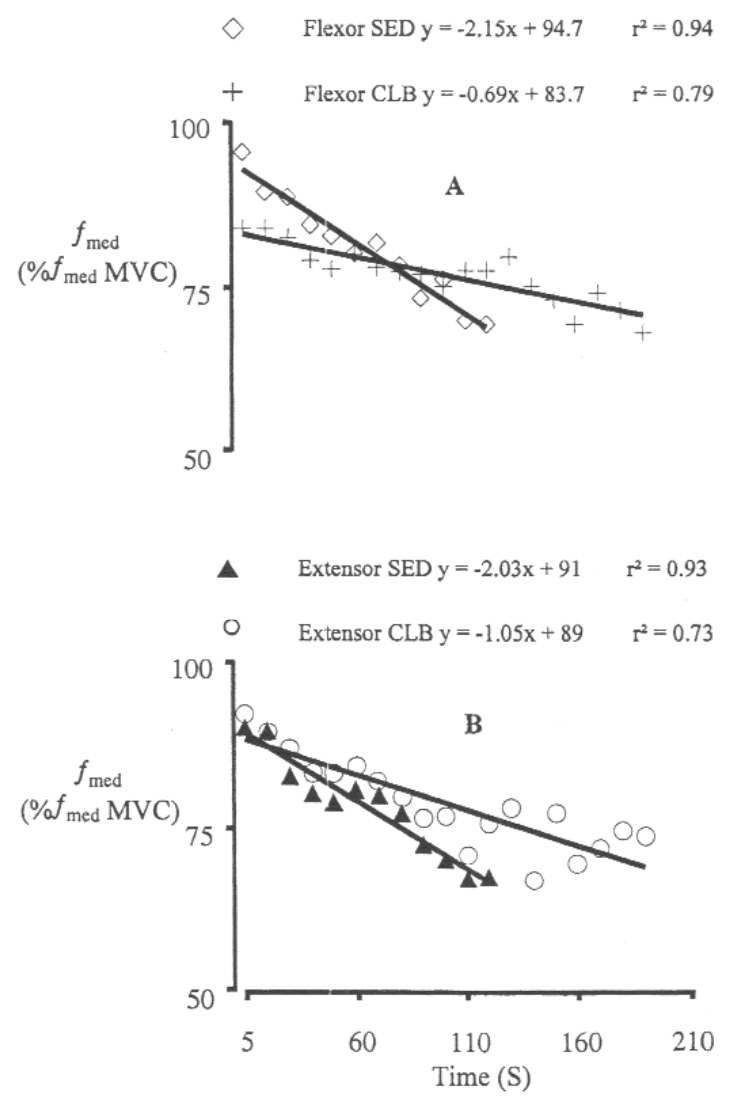

Fig. 2 Relative Median EMG power spectrum frequency $\left(f_{\text {med }}\right)$ over time during intermittent sub-maximal isometric contraction for flexor

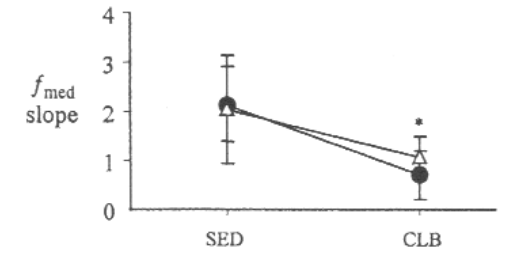

Fig. 3 Mean Relative Median EMG power spectrum frequency $f_{\text {med }}$ ) slopes across subjects $(n=10)$ in sedentary (SED) and climber (CLB) subjects. represents the flexor and $\triangle$ represents the extensor muscles. Error bars indicate standard errors. * indicates a significant difference between SED and CLB, whatever the muscle. 
The climber's time to exhaustion was double that of the nonclimbers'. This confirms that climbers have a greater degree of recovery between contractions, since they performed the exercise longer. This result was previously observed during similar exercise performed at lower intensity, i.e. $40 \%$ of maximal voluntary contraction [8].

The observed decrease of the median frequency in the nonclimbers equaled $23 \%$ of pre-fatigue values, whereas it amounted to $8 \%$ in elite climbers. In non-climbers, this decrease is in accordance with the model of fatigue of the finger flexors proposed by Petrofsky [13]. This model was based on the percentage of decrease of the median frequency from starting values. It ac curately describes fatigue in non-climbers, but does not seem suitable to predict fatigue in trained subjects as elite climbers. The differences observed in the slopes of the median frequency over time explain the durations of exercise noted in elite climbers and non-climbers. The rate of fatigue in non-climbers is more than twice as high as in elite climbers. In all subjects, the resting periods intersperse with periods of fatigue throughout the intermittent exercise. In elite climbers, thanks to their greater vaso-dilatory capacity [8], these periods may be sufficient to reverse the fatiguing effects on the contraction, reducing the accumulation of metabolites $[12,14]$, which induces a smaller re duction of the action potential velocity, and indirectly a smaller reduction of the median frequency. This may thus reduce the lack of force production at the peripheral level and consequently allow them to perform the exercise longer.

Within the limits of the present investigation, the results show that the surface EMC parameters can be used as a fatigue index during repeated fingertip isometric contractions under specific grip used in rock climbing. Elite climbers perform greater fingertip force and present time to exhaustion later than non-climbers, probably by reducing the fatigue at the peripheral level. Nevertheless, before conclusions can be drawn, additional investigations coupling EMG with other parameters (e. g. blood flow, metabolite concentration) must be conducted in other finger grip postures.

\section{References}

Basmajian JV, de Luca CJ. Muscles Alive. Baltimore: Williams \& Wilkins, 1985: 94

${ }^{2}$ Bigland-Ritchie B, Furbush F, Woods JJ. Fatigue of intermittent submaximal voluntary contractions: central and peripheral factors. J Appl Physiol 1986; 61: 421-429

${ }^{3}$ Billat V, Palleja P, Charlaix T, Rizzardo P, Janel N. Energy specificity of rock climbing and aerobic capacity in competitive sport rock climbers. J Sports Med Phys Fitness 1995; 35: 20-24

${ }^{4}$ Blackwell JR, Kornatz KW, Heath ME. Effect of grip span on maximal grip force and fatigue of flexor digitorum superficialis. Appl Ergon 1999; 30: 401 - 405

${ }^{5}$ Corolan B, Cafarelli E. Adaptations in coactivation after isometric resistance training. J Appl Physiol 1992; 73: 911 - 917

${ }^{6}$ Cutts A, Bollen SR Grip strength and endurance in rock climbers. Prosc Instn Mech Engrs 1993; 207: 87-92

${ }^{7}$ Eberstein A, Beattie B. Simultaneous measurement of muscle conduction velocity and EMG power spectrum changes during fatigue. Muscle Nerve $1985 ; 8: 768-773$

${ }^{8}$ Ferguson RA, Brown MD. Arterial blood pressure and forearm vascular conductance responses to sustained and rhythmic isometric exercise and arterial occlusion in trained rock climbers and untrained sedentary subjects. Eur J Appl Physiol 1997; 76: $174-180$

${ }^{9} \mathrm{Hägg} \mathrm{GM}$, Milerad E. Forearm extensor and flexor muscle exertion during simulated gripping work - an electromyographic study. Clin Biomech 1997; 12: 39-43

${ }^{10}$ Koukoubis T, Cooper L, Clisson R, Seaber A, Feagin J. An electromyographic study of arm muscles during climbing. Knee Surg Sports Traumatol Arthroscopy 1995; 3: 121-124

${ }^{11} \mathrm{Li}$ Z, Zatsiorsky V, Latash M. Contribution of the extrinsic and intrinsic hand muscles to the moments in finger joints. Clin Biomech 2000; 15: $203-211$

${ }^{12}$ Moustoufi-Moab S, Widmaier E, Cornett J, Gray G, Sinoway L. Forearm training reduces the exercise pressor reflex during ischemic rhythmic handgrip. J Appl Physiol 1998; 84: 277-283

${ }^{13}$ Petrofsky JS. Quantification through the surface EMG of muscle fatigue and recovery during successive isometric contractions. Aviat Space Environ Med 1981; 52: 545-550

${ }^{4}$ Pitcher JB, Miles TS. Influence of muscle blood flow on fatigue during intermittent human hand-grip exercise and recovery. Clin Exp Pharmacol Physiol 1997; 24: 471-476

${ }^{5}$ Psek JA, Cafarelli E. Behavior of coactive muscles during fatigue. J App Physiol 1992; 65: 251-257

${ }^{16}$ Rooks MD. Rock climbing injuries. Sports Med 1997; 23: 261 - 270

${ }^{17}$ Roy SH, O'Hara JM, Briganti M. Use of EMG spectral parameters to evaluate fatigue associated with pressure glove work. In: Anderson P, Hobart D, Danoff J (eds). Electromyographical Kinesiology. Amsterdam: Elsevier Science, 1991: 283-286

${ }^{18}$ Schweiser A. Biomechanical properties of the crimp grip position in Schweiser A. Biomechanical properties of the
rock climbers. J Biomech 2001; 34: 217-223

${ }^{9}$ Stephens JA, Taylor A. Fatigue of maintained voluntary muscle contraction in man. J Physiol 1972; 220: 1 - 18

${ }^{20}$ Valero-Cuevas FJ, Zajac FE, Burgar CG. Large index fingertip forces are produced by subject-independent patterns of muscle excitation. J Biomech 1998; 31: $693-703$

${ }^{21}$ Vollestad N, Sejersted I, Saugen E. Mechanical behavior of skeletal muscle during intermittent voluntary isometric contractions in humans. J Appl Physiol 1997; 83: 1557-1565 